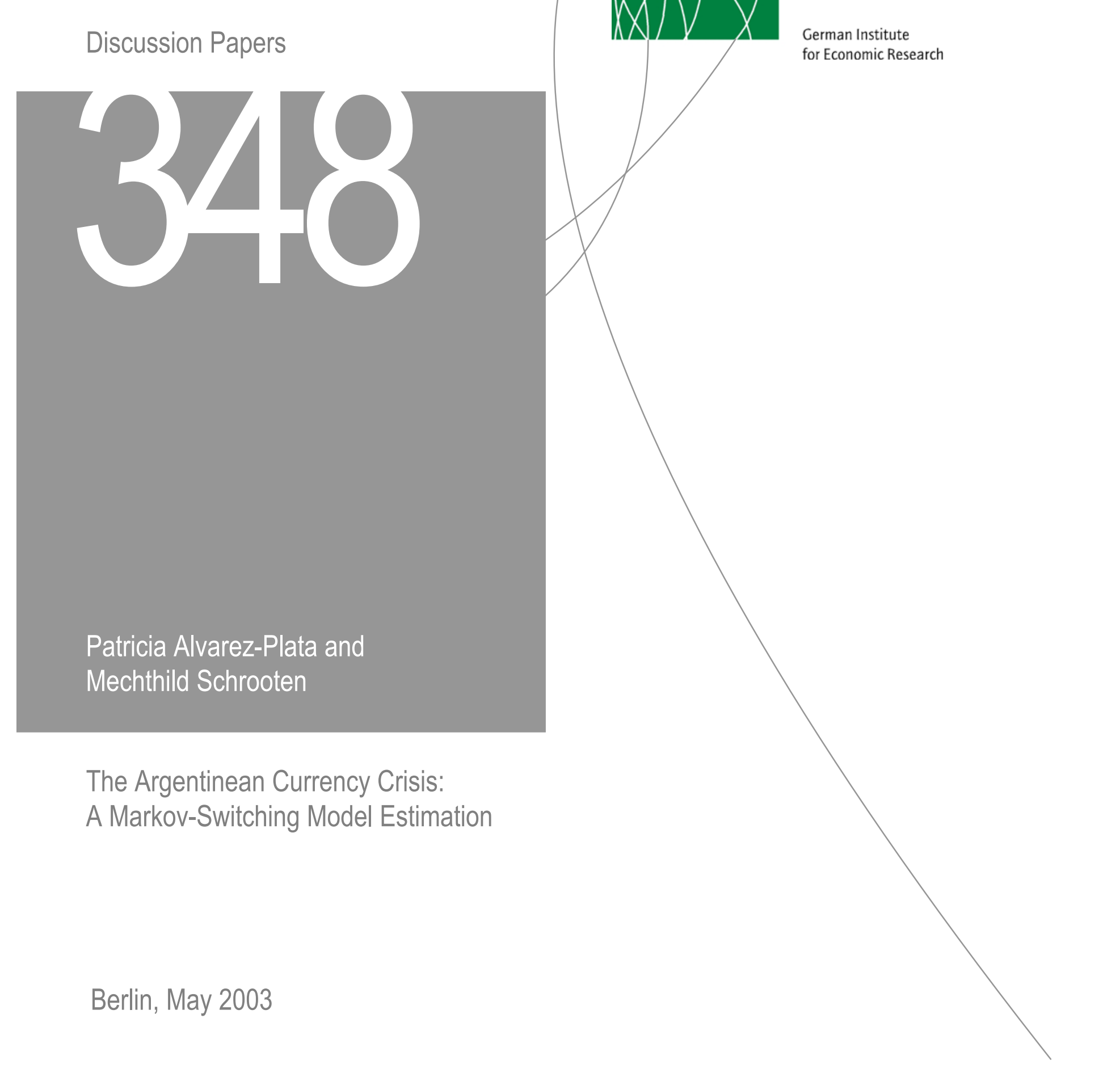


Opinions expressed in this paper are those of the author and do not necessarily reflect views of the Institute.

\section{DIW Berlin}

\section{German Institute}

for Economic Research

Königin-Luise-Str. 5

14195 Berlin,

Germany

Phone +49-30-897 89-0

Fax +49-30-897 89-200

www.diw.de

ISSN 1619-4535 


\title{
The Argentinean Currency Crisis: A Markov-Switching Model Estimation
}

\author{
Patricia Alvarez-Plata ${ }^{\S} \quad$ Mechthild Schrooten $₫$ \\ DIW Berlin DIW Berlin
}

May 19, 2003

\begin{abstract}
Despite the fact that Argentina has been suffering from a recession for years, the timing and severity of the recent currency crisis surprised most observers. This paper analyzes the role of fundamentals and self-fulfilling speculation in the Argentinean crisis. Arguing within a theoretical model of a fixed exchange rate system that allows for multiple equilibria, we show that the crisis, while being associated with weak and deteriorating fundamentals, cannot be explained by these macroeconomic factors alone. Estimating a univariate Markovswitching model, this paper shows that shifts in agents' beliefs did indeed also play a crucial role.
\end{abstract}

Keywords: Currency crises, Self-fulfilling speculation, Markov-switching models JEL classification: C22, F31, F36

${ }^{\S}$ DIW Berlin, Königin-Luise Straße 5, 14195 Berlin, Germany, e-mail: palvarez@diw.de,(corresponding author)

`DIW Berlin, Königin-Luise Straße 5, 14195 Berlin, Germany, e-mail: mschrooten@diw.de 


\section{Introduction}

The Argentinean currency board, which had started with overwhelming economic success, came to a sudden, harsh, and dramatic end. In January 2002, the period of the $1-t o-1$ peg between the US dollar and the Argentinean peso was over and the peso depreciated dramatically. Despite the fact that Argentina had been suffering from a recession for years, the timing and severity of the recent currency crisis surprised most observers.

Until recently, there is no consensus concerning the concrete causes of the Argentinean crisis. According to Calvo, Izquierdo, and Talvi (2002), the capital flow retrenchment after the Russian crisis of 1998 created a major real exchange rate misalignment and fiscal difficulties in Argentina. De la Torre, Levy Yeyati, and Schmukler (2002) find that Argentina fell into a growth-debt trap after 1998: when economic activity did not increase and credit from abroad dried up, the crisis became unavoidable. Feldstein (2002) argues that the crisis was due to exchange rate overvaluation and to an extremely high amount of foreign debt. On the whole, literature on the Argentinean crisis focuses on macroeconomic factors and so far has ignored factors associated with the agents' expectations and speculative behavior. While several papers analyze the vulnerability of the Argentinean economy prior to the crisis in a descriptive manner, proper empirical work has been scarce.

Therefore, this paper contributes a new perspective on at least three issues to the existing literature: First, the Argentinean crisis is analyzed within a theoretical framework that allows for multiple equilibria (Jeanne (1997)). An important feature of this model is that self-fulfilling expectations can arise only when the exchange rate arrangement has been undermined by weak fundamentals. Second, the empirical analysis is carried out by estimating a univariate non-linear Markov-switching model (based on Hamilton 1989) with two regimes. This model involves multiple structures that can describe time series behavior in different regimes. Thus it is able to capture more complex, dynamic patterns. Third, the empirical results 
clearly show that shifts in agents' beliefs could play a crucial role for the collapse of the Argentinean currency board.

The remainder of the paper is organized as follows. In Section 2 some stylized facts concerning the economic development in Argentina are presented. Section 3 presents the model and Section 4 analyzes - based on this model - the vulnerability of Argentina. In Section 5 the empirical approach of the Markov-switching AR models is discussed. Section 6 presents the empirical results. Finally, Section 7 concludes with a critical summary of the results.

\section{Stylized facts}

After its introduction in 1991, the Argentinean currency board was extremely effective: inflation came down soon and gross domestic product went up. Until 1998 Argentina outperformed most other countries in the region in terms of per capita growth. Furthermore, inflation dropped below US rates.

Initial macroeconomic difficulties occurred in the aftermath of the Mexican crisis of December 1994, but the Argentinean economy recovered relatively quickly; in 1996 positive growth rates were reported again. ${ }^{1}$ However, after the Asian (1997) and Russian (1998) crises and the devaluation of the Brazilian real (1999), Argentina was drawn into the swirls of the changing climate on international financial markets. Argentinean policy makers faced a dilemma: in order to make the country attractive to international investors, higher interest rates were necessary. However, increasing domestic interest rates always have a restrictive impact on economic activity. In this setting, GDP began to decrease (Figure A1).

Argentina had to face recession and deflation for a long period prior to the crisis. Nevertheless, traditional indicators for currency crises did not worsen significantly during the pre-crisis period. In 2001 did the external

\footnotetext{
${ }^{1}$ In 1995 the authorities recognized the importance of a particularly resilient financial system and banking system reforms were introduced quickly.
} 
debt-to-exports ratio, which was high during the whole period of the currency board (Figure A2) reach its lowest level since 1997. Additionally, the most prominent indicator for a currency crisis, the current account deficit, came down to less than 2 percent in 2001 (Figure A3). Thus, the current account deficit seemed to be sustainable in terms of its size. All in all, these important crisis indicators did not send appropriate warning signals during the immediate pre-crisis period.

\section{Theoretical Considerations}

The collapse of the Argentinean peso revived old debates about potential causes, symptoms, and patterns of currency crises. According to the first generation models (Krugman (1979)), currency crises come about due to a run on the international reserves, as speculators understand that the chosen fiscal and monetary policy is inconsistent with the pegged exchange rate. Thus, these theoretical models of fixed exchange rates explain speculative attacks against the domestic currency as a consequence of unsustainable developments in the "fundamentals" of an economy - such as rapidly growing budget deficits, high inflation, large and growing current account deficits, etc. "Second generation models" recognize that there are both benefits and costs of maintaining a peg and that investors' beliefs about whether a peg will hold or not can affect the government's cost of defending it. ${ }^{2}$ In these models, multiple equilibria and self-fulfilling crises may arise due to their inherent circularity - investors' expectations must be rational given the government policy and conversely the policy makers' behavior must be optimal given the expectations of the investors. ${ }^{3}$

In the following, we argue within an analytical framework in which both the fundamentals of an economy and self-fulfilling speculation might influence the emergence of a currency crisis (Jeanne (1997)). According to this

\footnotetext{
${ }^{2}$ See, for seminal literature, Obstfeld (1986) and Obstfeld(1996).

${ }^{3}$ Integrating banking and currency crises is the major aim of the so-called third generation models, which emerged just after the Asian crisis.
} 
model of a fixed exchange rate system, the government decides at each point in time whether to defend the peg or not. It is assumed that the policy makers maintain the peg as long as the net benefit of the exchange rate policy is positive. The net benefit $\left(B_{t}\right)$ depends on the gross benefit of the fixed peg $\left(b_{t}\right)$ and on the probability evaluated by the private sector at " $t-1$ " that the currency will be devaluated at " $\mathrm{t}$ " $\left(\pi_{t-1}\right)$ :

$$
B_{t}=b_{t}-\alpha \pi_{t-1}
$$

The gross benefit $\left(b_{t}\right)$ is an exogenous variable reflecting the fundamentals of the economy. It is assumed that the innovation in $b_{t}$ :

$$
\epsilon_{t}=b_{t}-E_{t-1} b_{t}
$$

is normally distributed with mean zero and variance $\sigma^{2}$. Thus, the innovation $\epsilon$ is characterized by a continuous and symmetric density function $f(\cdot)$ and is strictly increasing resp. decreasing in $(-\infty, 0)$ resp. $(0,+\infty)$.

Investors' expectations must be rational given the government's policy. At the same time the policy maker's behavior must be optimal given the expectations of the investors. Thus, the probability of devaluation in the current period is equal to the probability that the net benefit of the peg is negative in $\mathrm{t}+1$ :

$$
\pi_{t} \equiv \operatorname{Prob}_{t}\left[B_{t+1}<0\right]=\operatorname{Prob}_{t}\left[\epsilon_{t+1}<\alpha \pi_{t}-E_{t} b_{t+1}\right]
$$

Letting $\phi_{t}\left(=E_{t} b_{t+1}\right)$ represent all exogenous economic variables that influence the determination of the devaluation probability at $t$, equation (3) corresponds to

$$
\pi_{t}=F\left(\alpha \pi_{t}-\phi_{t}\right)
$$

where $\mathrm{F}(\cdot)$ represents the cumulative distribution of $\mathrm{f}(\cdot)$. There might be multiple solutions, since both the left and the right hand side of the equation depend positively on $\pi_{t}$, which means that a given level of the variable $\phi_{t}$ might be consistent with several levels of the devaluation probability $\pi_{t}$. 
As Jeanne (1997) shows, there are two necessary conditions for the existence of multiple equilibria. ${ }^{4}$ First, the slope of the cumulative distribution $F\left(\alpha \pi_{t}-\phi_{t}\right)$, when reaching its maximum (which corresponds to $\alpha f(0)$ ), has to be larger than one: ${ }^{5}$

$$
z \equiv \alpha f(0)>1 \Leftrightarrow \frac{\alpha}{\sigma \sqrt{2 \Pi}}>1 .^{6}
$$

Second, the fundamentals of the economy have to lie within a certain range (i.e. $\phi_{t} \in(\underline{\phi}, \bar{\phi}) .^{7}$ This range allowing for multiple equilibria is determined by two tangency conditions, which result in the following terms:

$$
\underline{\phi}=\alpha F\left(\sigma \sqrt{2 \ln \frac{\alpha}{\sigma \sqrt{2 \Pi}}}\right)-\sigma \sqrt{2 \ln \frac{\alpha}{\sigma \sqrt{2 \Pi}}}
$$

and

$$
\bar{\phi}=\alpha F\left(-\sigma \sqrt{2 \ln \frac{\alpha}{\sigma \sqrt{2 \Pi}}}\right)+\sigma \sqrt{2 \ln \frac{\alpha}{\sigma \sqrt{2 \Pi}}} .
$$

To resume, self-fulfilling speculation may arise when the structural parameters of the economy allow for multiple equilibria in market expectations and when the fundamentals of the economy lie within a certain interval. Then a jump from a "low" to a "high" devaluation probability may or may not happen, depending on the "animal" spirits of the market.

\footnotetext{
${ }^{4}$ In the case of multiple equilibria, the devaluation probability may take three different values. For an explanation see also Jeanne (1997).

${ }^{5}$ If in contrast the slope of the cumulative distribution is smaller than one everywhere, i.e. $z<1$, the devaluation probability is uniquely determined by $\phi_{t}$ and decreases with it.

${ }^{6}$ See Jeanne (1997) for the proof based on a graphical representation of equation (4).

${ }^{7}$ If in contrast the fundamentals are very good (i.e. $\phi>\bar{\phi}$ ), the devaluation probability is uniquely defined and close to zero. Accordingly, if the fundamentals are very bad (i.e. $\phi<\underline{\phi}$ ), the devaluation probability is also uniquely defined and close to one.
} 


\section{How vulnerable was Argentina?}

In the years preceding the Argentinean crisis, fundamentals were weak for an extended period of time. Nevertheless there were no warning signals indicating a further worsening of these macroeconomic conditions prior to the crisis. As a consequence, the concrete timing of the Argentinean currency crisis surprised most observers. Can the currency crisis be explained by a shift in expectations? Using the theoretical framework presented above, the following question arises: Were the conditions necessary for the existence of multiple equilibria fulfilled?

Therefore, we first have to prove whether the slope of the cumulative distribution $F\left(\alpha \pi_{t}-\phi_{t}\right)$ is larger than one (at its maximum). As does Masson (1998), we define $\alpha$ as the product of foreign debt (D) and the expected devaluation size $(\delta)$ :

$$
\alpha=\delta D^{8}
$$

Under this assumption we calculate $\mathrm{z}$ as in the model of Jeanne. Table 1 shows the results. Indeed, $z>1$ holds during the pre-crisis period. Thus, the first condition necessary for the existence of multiple equilibria is satisfied.

Second, we have to prove whether the fundamentals lie within the range of multiple equilibria. For this purpose we approximate the vulnerability of the Argentinean economy as in Masson (1998):

$$
\phi_{t}=E\left(T B_{t}\right)+R_{t}-\bar{R}-r_{t}^{\star} D_{t}
$$

where $E\left(T B_{t}\right)$ is the expected value from trade balance as a percentage of GDP, $R_{t}$ the level of international reserves as a percentage of GDP, $\bar{R}$ the threshold value of international reserves (in the following assumed to be zero), $r^{\star}$ the foreign interest rate (U.S. rate) and $D_{t}$ the external debt as a percentage of GDP. ${ }^{9}$ In order to approximate the expected value from trade

\footnotetext{
${ }^{8}$ Following Masson, the expected devaluation size $\delta$ is assumed to be 25 percent. An estimation for $\sigma$ results from the regression of an autoregressive process (see below).

${ }^{9}$ The following variables can be motivated by a simple balance of payment model.
} 
Table 1: Argentina's vulnerability

\begin{tabular}{|c|c|c|c|c|c|c|c|c|}
\hline Year & $D_{t}$ & $R_{t}$ & $T B_{t}$ & $r_{t}^{\star}$ & $z_{t}$ & $\underline{\phi_{t}}$ & $\overline{\phi_{t}}$ & $\phi_{t}$ \\
\hline \hline 1995 & 38.42 & 5.53 & -0.43 & 5.51 & 1.80 & 2.57 & 7.03 & 3.11 \\
1996 & 40.64 & 6.65 & -0.67 & 5.02 & 1.90 & 2.75 & 7.42 & 4.13 \\
1997 & 42.70 & 7.62 & -2.24 & 5.07 & 2.00 & 2.91 & 7.76 & 3.85 \\
1998 & 47.48 & 8.28 & -2.55 & 4.81 & 2.22 & 3.38 & 8.49 & 4.16 \\
1999 & 51.24 & 9.26 & -1.75 & 4.66 & 2.40 & 3.74 & 9.07 & 5.62 \\
2000 & 51.49 & 8.85 & -0.64 & 5.84 & 2.41 & 3.76 & 9.11 & 5.39 \\
2001 & 52.21 & 5.41 & 1.24 & 3.45 & 2.44 & 3.83 & 9.22 & 4.51 \\
\hline
\end{tabular}

balance, an autoregressive process of order one for $T B_{t}$ from 1992 to 2001 is estimated. ${ }^{10}$ The standard error of the regression is taken as an estimate for $\sigma$, i.e. the standard deviation of innovations to trade balance.

Looking at Table 1 , we see at a glance that the second condition necessary for the existence of multiple equilibria is also fulfilled. On the whole it is shown that Argentina was highly vulnerable long before the crisis.

\section{Empirical Approach: The Non-linear Markov- switching AR models}

In the empirical literature on currency crises, in the majority of cases, the role of country-specific economic fundamentals in causing currency crises is estimated by using a linear function. However, an important shortcoming of estimating a linear function is that it ignores the possibility that shifts in expectations and private sector beliefs may also cause crises (Fratzscher (2002)). Since the determinants of these changes tend to be unobservable, it is very difficult to develop an appropriate empirical method. Thus, using a Markov-switching model might be helpful. In this class of models it is

\footnotetext{
${ }^{10}$ Quarterly data are used.
} 
assumed that the parameters of the underlying data generating process of the observed time series depend on an unobservable state variable.

The Markov-switching model, also known as regime switching model, developed by Hamilton (1989), is one of the most popular non-linear time series models. In this model, non-linearities arise if processes are confronted with discrete shifts in regime. By permitting switching between these $\mathrm{N}$ regimes, in which the dynamic behavior of series is markedly different, more complex dynamic patterns can be characterized. The switching mechanism is controlled by an unobservable state variable that follows a first-order Markov chain. Thus, the probability that the state variable $s_{t}$ equals some particular value $\mathrm{j}$ depends on the past only through the most recent value $s_{t-1}: 11$

$$
P\left\{s_{t}=j \mid s_{t-1}=i, s_{t-2}=k, \ldots\right\}=P\left\{s_{t}=j \mid s_{t-1}=i\right\}=p_{i j} .
$$

As such, a structure may prevail for a random period of time, and will be replaced by another structure when switching takes place. The transition probability $p_{i j}$ gives the probability that state $\mathrm{i}$ will be followed by state $\mathrm{j}$. Clearly, the transition probabilities satisfy $p_{i 1}+p_{i 2}+\ldots+p_{i N}=1 .{ }^{12}$ They can be collected in an $(\mathrm{N} x \mathrm{~N})$ matrix $\mathrm{P}$ known as the transition matrix:

$$
P=\left(\begin{array}{cccccc}
p_{11} & p_{12} & \cdot & \cdot & \cdot & p_{1 N} \\
p_{21} & p_{22} & . & . & \cdot & p_{2 N} \\
\vdots & \vdots & . & . & \cdot & \vdots \\
p_{N 1} & p_{N 2} & \cdot & . & . & p_{N N}
\end{array}\right)
$$

In the following we will focus on a two-regime Markov-switching AR model of order $p(\mathrm{MS}(2)-\mathrm{AR}(\mathrm{p})$ model). In the most general specification of this model, all parameters of the autoregressions are conditioned on the state $s_{t}$ such that:

$$
y_{t}= \begin{cases}v_{1}+a_{11} y_{t-1}+\ldots+a_{p 1} y_{t-p}+u_{1 t} & \text { if } s_{t}=1 \\ v_{2}+a_{12} y_{t-1}+\ldots+a_{p 2} y_{t-p}+u_{2 t} & \text { if } s_{t}=2\end{cases}
$$

\footnotetext{
${ }^{11}$ For a more extensive discussion of Markov chains, see Hamilton (1994).

${ }^{12} \mathrm{~A}$ limitation of Hamilton's model is that the transition probabilities are assumed to be exogenous and constant over time.
} 
with $u_{t} \sim \operatorname{NID}\left(0, \sigma_{s_{t}}^{2}\right)$. As the above $\operatorname{MS}(2)$-AR(p) model illustrates, Markovswitching models can be specified with regime dependent autoregressive parameters, a regime dependent mean or intercept, and with hetero- or homoskedastic error terms . Furthermore, observable exogenous variables can be included in the system. ${ }^{13}$ However, for empirical application it may be better to use a model where only some parameters depend on the state of the Markov chain. There are different ways to estimate the Markov-switching model; see for example Hamilton (1990) and Kim and Nelson (1999). In this paper, a Markov-switching model is estimated by implementing the Expectation Maximization (EM) algorithm, programmed in Ox. ${ }^{14}$

\section{$6 \quad$ Empirical Results}

Using a non-linear Markov-switching model allows us to analyze the dynamics of the devaluation probability in Argentina. The estimation results are interpreted, within the theoretical framework of the currency crisis model described above, taking regime shifts as jumps between different devaluation probabilities. According to the theoretical model, these jumps are generated by shifts in expectations of investors.

To prove whether shifts in expectations of private investors influenced the Argentinean crisis of 2002, we estimate a Markov-switching model with two regimes. ${ }^{15}$ The exogenous shifts in expectations are modelled as switching autoregressive parameters and changes in the error variance [i.e., we estimate a MSAH (2) ARX (1) model]. The devaluation probability is assumed to be a function of the pressure at the exchange market. This is measured

\footnotetext{
${ }^{13}$ In that case the system is denoted MS(M)-VARX(p). A broad discussion of systems with exogenous variables is given by Krolzig (1997).

${ }^{14} \mathrm{~A}$ wide class of Markov-switching models can be estimated by using this program written by Hans-Martin Krolzig. The EM algorithm was first introduced by Dempster, Laird, and Rubin (1977). It is designed for a general class of models, in which the observed time series depends on some unobservable stochastic variables.

${ }^{15} \mathrm{~A}$ model with two regimes is estimated, since within the theoretical model presented above, two of the three equilibria are dynamically stable. See also Jeanne(1997).
} 
by an index of speculative pressure constructed as a weighted average of monthly exchange rate changes $(\Delta e)$, interest differential changes $\left(\Delta i-i^{\star}\right)$ and international reserve changes $(\Delta R)$ :

$$
\text { Index of pressure } \equiv \eta(\Delta e)+\varphi\left(\Delta\left(i-i^{\star}\right)\right)-\psi(\Delta R)
$$

with $\eta, \varphi$ and $\psi$ as weights and $i^{\star}$ as the US interest rate. The weights are calculated as the inverse of the series' standard deviation in the past. ${ }^{16}$

A broad set of fundamentals, which are usually expected to influence the probability of devaluation, is employed:

- Capital account indicators: international reserves, ratio of broad money to gross international reserves, exchange rate between the Argentinean peso and the Brazilian real.

- Current account indicators: exports, imports.

- Financial sector indicators: stock of commercial bank deposits, domestic credit, ratio of lending to deposit rate, M1.

- Real sector indicator ${ }^{17}$ : output.

Our sample includes monthly data between January 1994 and December 2001, the longest period for which appropriate data is available during the Argentinean currency board. ${ }^{18}$ We use first differences of all variables, which are stationary. To check this, ADF- and Perron-Tests are executed.

After excluding variables which were insignificant in both regimes, we get the results presented in Table 2. All variables, with the exception of M1, have the expected sign.

\footnotetext{
${ }^{16}$ Indices of speculative pressure have been used in various studies, including Eichengreen, Rose and Wyplosz (1995) and Kaminsky and Reinhart (1999).

${ }^{17}$ Unfortunately, the Argentinean unemployment rate, which is theoretically expected to influence the costs of the fixed exchange rate system, was not available.

${ }^{18}$ Data are taken from the International Financial Statistics of the IMF as well as from national statistics.
} 
Table 2: Estimation results

\begin{tabular}{|c|c|c|c|c|}
\hline & \multicolumn{2}{|c|}{ Regime 1 } & \multicolumn{2}{c|}{ Regime 2 } \\
& Coefficient & t-value & Coefficient & t-value \\
\hline \hline Index of Pressure(-1) & 0.1591 & 1.88 & -0.72 & -8.88 \\
\hline M2/Reserves & 0.012 & 11.66 & 0.002 & 1.8 \\
\hline M2/Reserves(-1) & 0.001 & 0.072 & 0.011 & 6.97 \\
\hline Bank Deposits & -0.011 & -3.285 & -0.084 & -17.48 \\
\hline Domestic Credit & -0.005 & -1.15 & 0.035 & 5.23 \\
\hline Imports & 0.002 & 0.355 & 0.012 & 14.33 \\
\hline M1 & 0.003 & 2.28 & -0.013 & -7.533 \\
\hline Output (-7) & -0.001 & -0.977 & -0.02 & -7.57 \\
\hline log-likelihood (MSAH) & 585.3137 & & & \\
\hline log-likelihood (linear) & 521.2686 & & & \\
\hline
\end{tabular}

For the sake of comparison, we also included the log likelihood of a linear regression of the index of pressure. The higher log likelihood of the Markovswitching model suggests that this model performs significantly better than the linear regression. ${ }^{19}$

The estimated matrix of transition probabilities shows that two fairly persistent regimes do exist:

$$
\widehat{P}=\left(\begin{array}{ll}
0.9184 & 0.0816 \\
0.2750 & 0.7250
\end{array}\right)
$$

Figure (1) exhibits the filtered and the smoothed probabilities of being in regime 1 or regime $2 .{ }^{20}$ Regime 1 is a so-called "tranquil" regime, during

\footnotetext{
${ }^{19}$ Unfortunately, this hypothesis cannot be formally tested using the usual likelihood ratio test since one of the regularity conditions necessary for this test does not hold (Hamilton, 1994, 1996).

${ }^{20}$ The filtered probability estimates are based on information up to time point $t$. In contrast the smoothed probability estimates use full sample information to make an inference about the unobserved regimes.
} 
which the probability of devaluation is low, whereas Regime 2 represents times of high economic tensions and reflects periods during which the devaluation probability is considerably higher. This is reflected also in the fact that many of the variables, which seem to have a significant influence on the devaluation probability in Regime 2, are not significant in Regime 1.

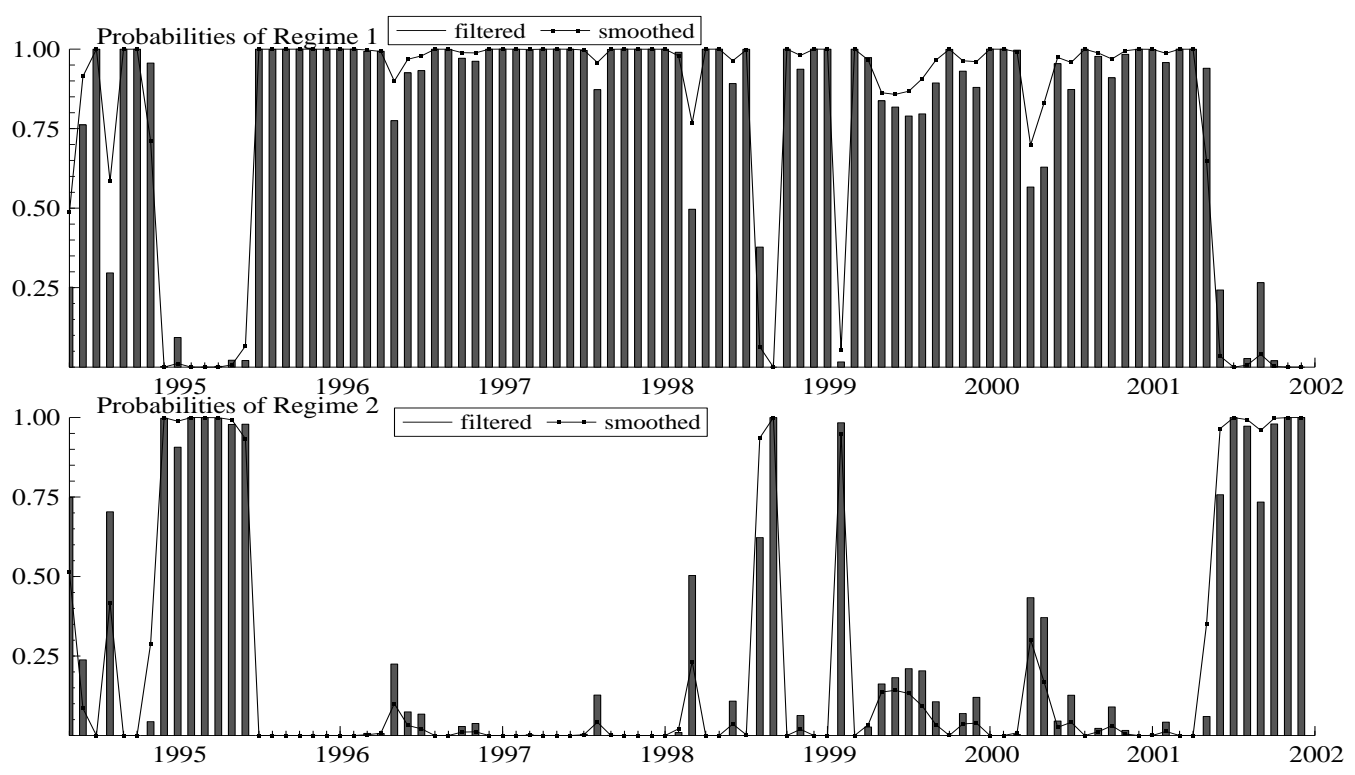

Figure 1: Probabilities of Regime 1 and Regime 2

The figure shows that several shifts between the regimes took place over time. What might have caused these shifts in expectations? Can we detect any exogenous shocks?

The results present a shift of regimes in 1995. Regime 2, the one with the higher devaluation probability, was then in effect for about six months. Indeed, 1995 was a difficult year for the Argentinean currency board. In December 1994 the Mexican crisis emerged, affecting the whole region. In this context, the Argentinean currency came under pressure and a domestic banking crisis occurred in 1995. As a consequence of the domestic and international turmoil, the Argentinean currency board was softened. This policy decision can be interpreted as a temporary abandonment of the pegged exchange rate regime. In other words, Argentina was suffering from several characteristics of a currency crisis in 1995. Nevertheless, no depreciation 
took place. And, as Figure (1) shows, a switch back to Regime 1 occurred after several months.

Analyzing the next years, only short term shifts from Regime 1 to Regime 2 can be detected. These shifts in expectations can be explained mainly as the consequences of external shocks: the Asian crisis in 1997 and the Russian crisis of 1998 led to new evaluations of emerging economies from the perspective of international investors. In 1999 it was certainly the Brazilian currency crisis which lead to the regime shift. However, a common feature of all these external shocks is that they had only a short-term influence on the devaluation expectations. In all these cases Regime 1, the regime with low devaluation probability, soon regained force.

A last important shift in expectations took place in the second half of 2001. How can this shift be explained? There was no international financial crisis abroad, which could have influenced a shift in expectations of investors. Thus, domestic factors must have played a crucial role. Looking at Argentina in 2001, several factors can be found which might have supported the view that the depreciation of the peso became unavoidable: First, the political chaos resulted in several replacements of economic ministers. Second, in June 2001, a dual exchange rate was introduced. Third, a new construction of the currency board was approved by congress. This reconstruction was designed as a weighted peg of the peso to both the US dollar and the euro. Fourth, in the last few months of 2001, several forms of quasi-money were introduced, which was a clear indicator that the currency board was drying out. Since there were no impulses for a re-switch to Regime 1, the Argentinean currency board came under more and more pressure. In January 2002, the government did not see any alternative to the abolition of the pegged exchange rate. Immediately the peso depreciated sharply and Argentina was sucked into the maelstrom of a currency crisis. 


\section{Conclusions}

The fundamentals in Argentina were weak over a long period prior to the currency crisis of 2002. Arguing within the model of Jeanne, we have shown that from 1995 onwards, Argentina's fundamentals were within the zone of multiplicity and self-fulfilling speculation could arise. According to Jeanne, switches between multiple equilibria, leading to a change in the devaluation probabilities, are caused by changes in the expectations of private investors.

In the empirical part of this paper we estimated a Markov-switching model with two regimes. Regime shifts are assumed to reflect changes in expectations. We show that there are two different regimes. In fact, Argentina was subject to several shifts in expectations over time. During the years 1996 to 2000, all switches to the regime with the higher devaluation probability - Regime 2 - were short-term switches; i.e. a switch to Regime 2 was always accompanied by a rapid switchback to Regime 1. The situation was totally different in the immediate period prior to the crisis of 2002: now Regime 2 was persistent; no re-switching was observable. This persistence of Regime 2 is the major difference between this and other periods.

All in all, it appears to be legitimate to assume that a shift in expectations had an important influence on the occurrence of the currency crisis in Argentina. Additionally, the length of the period during which the regime with the higher devaluation probability is in effect seems to play an important role for the occurrence of a currency crisis - at least in Argentina.

There are several interesting directions in which this study could be extended. We have argued within a Markov-switching model with constant transition probabilities and assumed that regime shifts are due to shifts in expectations. However, it remains an open question whether external factors (contagion) and/or domestic events (political factors) have influenced expectations of investors in an empirically measurable way. For this purpose, a Markov-switching model with time-varying transition probability would have to be estimated. In addition, analyzing a broader set of currency crises would be a natural extension of this study. 


\section{References}

Calvo, G., Izquierdo, A., Talvi E., 2002. Sudden Stops, the Real Ex-

change Rate and Fiscal Sustainability: Argentina's Lessons. Mimeo, InterAmerican Development Bank.

De la Torre, A., Levy Yeyati, E., Schmukler, S., 2002. Argentina's Financial Crisis: Floating Money, Sinking Banking. Mimeo, World Bank.

Dempster, A., Laird, N., Rubin, D., 1977. Maximum likelihood estimation from incomplete data via the EM algorithm. Journal of Royal Statistical Society, 39, 1-38.

Eichengreen, B., Rose, A., Wyplosz, C., 1994. Speculative Attacks on Pegged Exchange Rates: An Empirical Exploration with special Reference to the European Monetary System. National Bureau of Economic Research, Working Paper 4898.

Eichengreen, B., Rose, A., Wyplosz, C., 1995. Exchange market mayhem: the antecedents and aftermath of speculative attacks. Economic Policy 21, 251-312.

Feldstein, M., 2002. Argentina's Fall: Lessons from the Latest Financial Crisis. Foreign Affairs, March/April.

Fratzscher, M., 2002. On currency crises and contagion. European Central Bank Working Paper 139.

Hamilton, J., 1989. A new approach to the economic analysis of nonstationary time series and the business cycle. Econometrica 57, 357-384.

Hamilton, J., 1990. Analysis of time series subject to changes in regime. Journal of Econometrics, 45, 39-70.

Hamilton, J., 1994. Time Series Analysis. Princeton: Princeton University Press. 
Hamilton, J., 1996. Specification testing in Markov-switching time-series models. Journal of Econometrics 70, 127-157.

Jeanne, O., 1997. Are currency crises self-fulfilling? A test. Journal of International Economics 43, 263-286.

Jeanne, O., Masson, P., 2000. Currency crises, sunspots and Markovswitching regimes. Journal of International Economics 50, 327-350.

Kaminsky, G., Reinhart, C., 1999. The Twin Crises: The Causes of Banking and Balance-of-Payments Problems. American Economic Review 89, 473500 .

Kim, C., Nelson, C., 1999. State Space Models with Regime Switching, Classical and Gibbs Sampling Approaches with Applications. Cambridge, MA: MIT Press.

Krolzig, H.-M., 1997. Markov-Switching Vector Autoregressions. Berlin, Heidelberg, New York: Springer Verlag.

Krugman, P., 1979. A model of balance-of-payments crises. Journal of Money, Credit and Banking 11, 311-325.

Krugman, P., 1996. Are currency crises self-fulfilling? Paper presented at the NBER Macro Annual Conference.

Kuan, C.-M., 2002. Lecture on the Markov Switching Model, Mimeo, Institute of Economics, Taiwan.

Masson, P., 1998. Contagion: monsoonal effects, spillovers, and jumps between multiple equilibria. International Monetary Fund Working Paper.

Obstfeld, M., 1986. Rational and Self-Fulfilling Balance-of-Payments Crises. American Economic Review 76, 72-81.

Obstfeld, M., 1996. Models of Currency Crises with Self-fulfilling Features. European Economic Review 40, 1037-1047. 
Sachs, J., Tornell, A., Velasco, A., 1996. The Mexican peso crisis: Sudden death or death foretold?. Journal of International Economics 41, 265-283.

Van Norden, S., 1996. Fixed exchange rates: Credibility, flexibility and multiplicity. European Economic Review 40, 1023-1035. 


\section{Appendix}

Figure A1

Gross Domestic Product 1990 - 2001

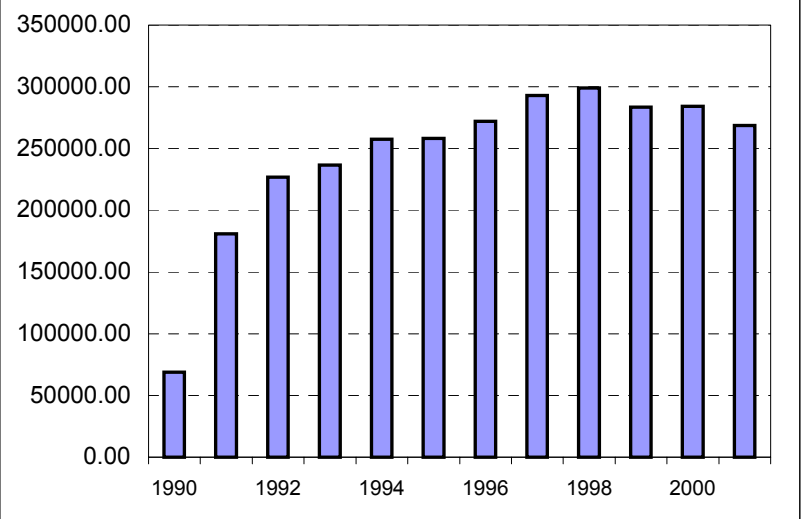

Figure A2

External Debt to Exports 1991 - 2001 in percent

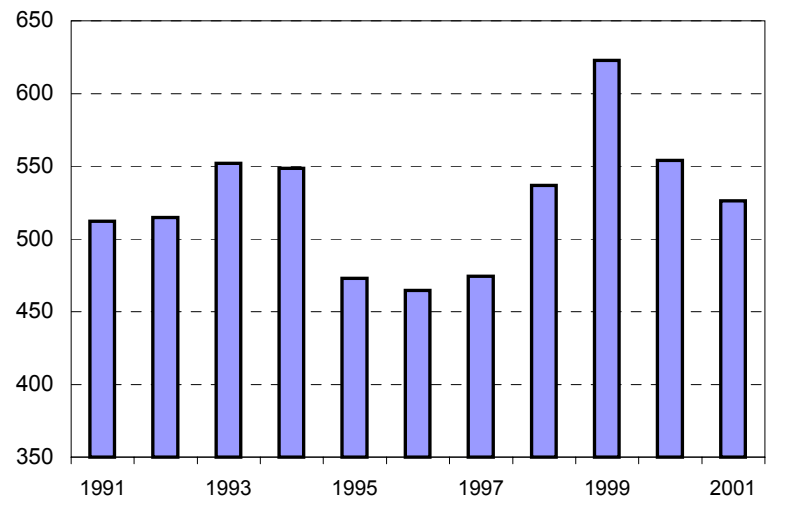

Figure A3

Current Account Deficit in percent of GDP 1991-2001

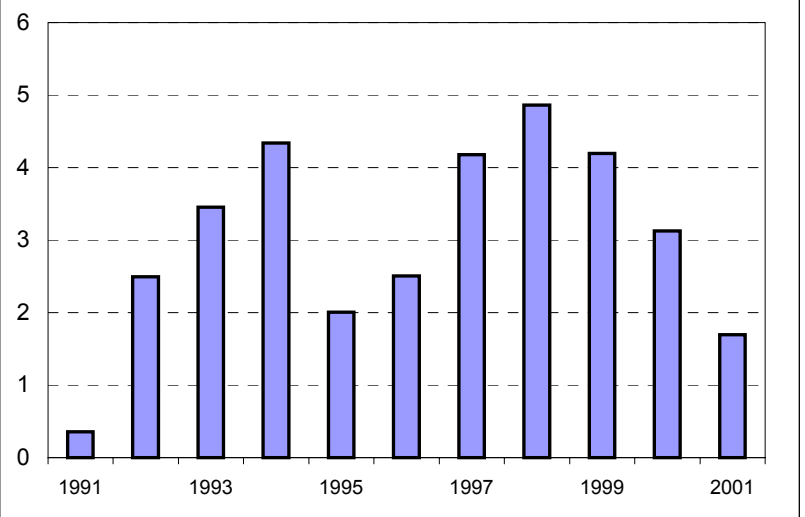

